\title{
Chapter 19 \\ Evolution and Protection of Cerebral \\ Infarction Evaluated by PET and SPECT
}

\section{Eku Shimosegawa}

\begin{abstract}
Since cerebral infarction results from a reduction of cerebral blood flow (CBF) by the occlusion or stenosis of carotid or intracranial arteries, CBF is a primary parameter to predict of ischemic brain injury. Single-photon emission tomography (SPECT) and positron emission tomography (PET) contributed to evaluate loss of cerebral autoregulation, uncoupling state between CBF and brain metabolism, and ischemic penumbra. Measurement of $\mathrm{CBF}$ and oxygen metabolism by ${ }^{15} \mathrm{O}$ PET revealed the process of infarct growth in hyperacute stage of cerebral infarction and areas with depressed oxygen metabolism, but normal water diffusion in magnetic resonance imaging (MRI) was termed as "metabolic penumbra." Recently, some researchers shed light on the role of glial cells in the energy metabolism of the brain and ${ }^{11} \mathrm{C}$-acetate PET and demonstrated that astrocytic energy metabolism in TCA cycle was protective against ischemia. SPECT and PET studies for secondary reaction after ischemia (i.e., selective neuronal loss by

${ }^{123}$ I-iomazenil SPECT and ${ }^{11} \mathrm{C}$-flumazenil PET, tissue hypoxia by ${ }^{18} \mathrm{~F}$-FMISO PET, and neuroinflammation by TSPO-PET) are expected as new biomarkers. Combining these imaging biomarkers with classical CBF measurement may contribute to develop innovative drugs for pharmacological neuroprotection in the therapy of cerebral infarction.
\end{abstract}

Keywords Cerebral infarction $\bullet$ SPECT $・$ PET $・$ Hypoxia $・$ TSPO-PET

\subsection{Introduction}

Cerebral infarction results from a reduction in cerebral blood flow (CBF) arising from the occlusion or stenosis of carotid or intracranial arteries, and the progression of this event typically ends with the necrosis of various brain tissue components, including neurons. Since tissue damage varies according to the severity of brain

\footnotetext{
E. Shimosegawa, MD, PhD ( $ه)$

Department of Molecular Imaging in Medicine, Graduate School of Medicine,

Osaka University, 2-2 Yamadaoka, Suita, Osaka 565-0871, Japan

e-mail: eku@mi.med.osaka-u.ac.jp 
ischemia, $\mathrm{CBF}$ is a primary parameter for predicting the extent of ischemic brain injury.

Positron emission tomography (PET) and single-photon emission computed tomography (SPECT) have contributed to the elucidation of the disease process responsible for brain ischemia from an acute to chronic stage. PET studies have mainly measured $\mathrm{CBF}$ and oxygen metabolism but have been expanded to include the detection of neuronal loss, tissue hypoxia, and neuroinflammation. Quantitative ${ }^{15} \mathrm{O}$ PET measurements can provide information on $\mathrm{CBF}$, the cerebral metabolic rate of oxygen $\left(\mathrm{CMRO}_{2}\right)$, the cerebral blood volume $(\mathrm{CBV})$, and the oxygen extraction fraction $(\mathrm{OEF})$, and these parameters enable impaired cerebral autoregulation and the uncoupling of perfusion and metabolism to be diagnosed based on absolute values. The SPECT studies can visualize the magnitude and extent of ischemia in a clinical setting. Neurons are more vulnerable than other cell groups in the brain, and selective neuronal loss sometimes occurs in patients with mild to moderate brain ischemia. PET and SPECT are advantageous for demonstrating this type of brain injury, which cannot be visualized by comparing computed tomography (CT) and magnetic resonance imaging (MRI) findings. PET imaging of tissue hypoxia is expected to distinguish permanent and temporal ischemic areas surrounding the ischemic core. Translocator protein (TSPO) PET can represent neuroinflammation in areas with evolving infarcts and may become a biomarker for neuroprotective therapy. Recently, important roles of astrocytes in the energy metabolism of the brain have been reported. The imaging of astrocytes using ${ }^{11} \mathrm{C}$-acetate PET may provide a sensitive marker for evaluating glial metabolism in the ischemic brain. The purpose of using these imaging probes depends on the course or stage of

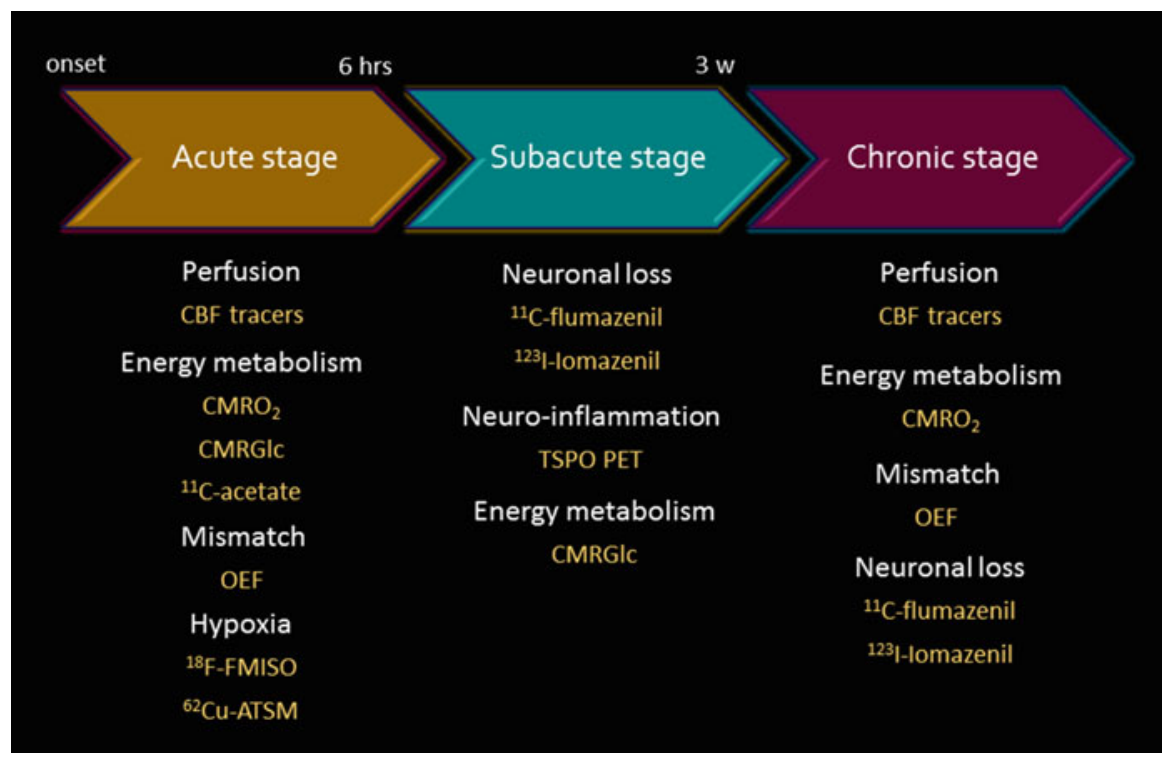

Fig. 19.1 Time course of infarct evolution and related PET/SPECT imaging 
cerebral infarction (Fig. 19.1). In this chapter, we introduce the use of PET and SPECT imaging in studies to clarify the process of cerebral infarction.

\subsection{Perfusion and Oxygen Metabolism in Brain Ischemia}

CBF is a key parameter of ischemic brain damage that can be quantitatively measured using PET and SPECT. A decrease in the cerebral perfusion pressure (CPP) induces primary damage to the supply of oxygen and energy substance to the brain. Protective mechanisms against reductions in the CPP can be evaluated using PET and SPECT. The first mechanism is "cerebral autoregulation," the origin of which is cardiac pump function. $\mathrm{CBF}$ is constant within a mean arterial blood pressure (MABP) range of $60-160 \mathrm{mmHg}$ [1]. To maintain a constant $\mathrm{CBF}$, cerebral precapillary arterioles can dilate when the CPP decreases and can constrict when the CPP increases. Although this mechanism of dilation and constriction for cerebral autoregulation remains unclear, recent studies have indicated that $\mathrm{CBF}$ control is initiated in the cerebral capillaries, where pericytes can constrict capillaries in response to the effect of noradrenaline [2]. Cerebral autoregulation is disturbed by brain ischemia [3], and its capacity can be estimated using the cerebral vasoreactivity (CVR) to the change in the arterial partial pressure of carbon dioxide $\left(\mathrm{PaCO}_{2}\right)$. In SPECT studies, acetazolamide, which is another vasodilating agent, is used to test CVR. A reduced CVR in patients with steno-occlusive carotid artery disease is a major predictor of stroke recurrence [4, 5].

By combining this information with data on CBF and oxygen metabolism measured using ${ }^{15} \mathrm{O}$ PET, we can evaluate other protective states against $\mathrm{CPP}$ reduction (Fig. 19.2). When cerebral autoregulation is functioning well, CBF remains normal and the $\mathrm{CBV}$ increases, indicating the dilatation of collateral vessels. When the CPP is reduced beyond the point of compensation by vasodilatation, the cerebral autoregulation is exhausted and the CBF begins to decrease.

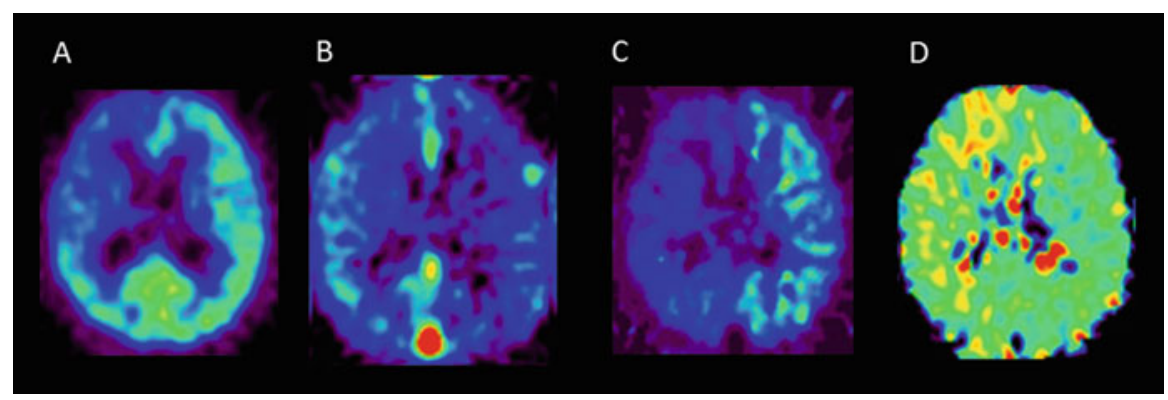

Fig. 19.2 ${ }^{15} \mathrm{O}$ PET images in a patient with right carotid and MCA occlusion. PET images of (a) CBF, (b) CBV, (c) CPP, and (d) OEF. The CPP images were created by dividing CBF and CBV. The area with a severe CPP reduction corresponded to the area with an elevated OEF (misery perfusion) 


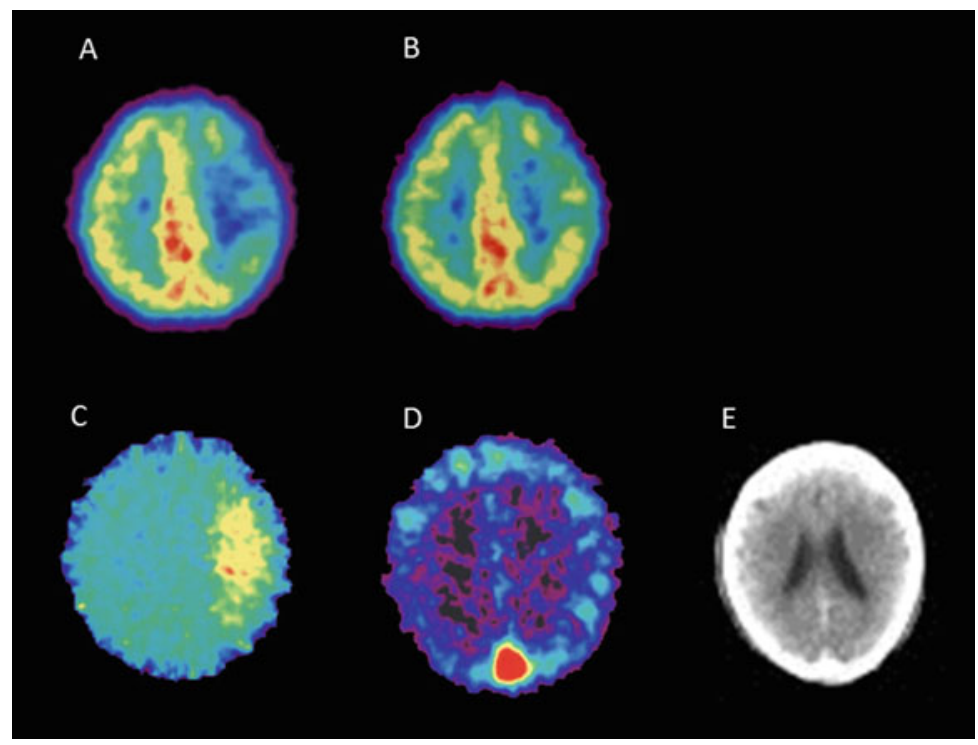

Fig. 19.3 Misery perfusion in a patient with acute left MCA occlusion. PET images of (a) CBF, (b) $\mathrm{CMRO}_{2}$, (c) OEF, and (d) $\mathrm{CBV}$ examined on the day of stroke onset. The CBF in the left MCA territory reduced, whereas the $\mathrm{CMRO}_{2}$ in the corresponding area was relatively preserved. The OEF was elevated in the same area, indicating an uncoupled state between perfusion and oxygen metabolism (misery perfusion). A CT image obtained on the same day (e) did not show any morphological changes

When $\mathrm{CMRO}_{2}$ is preserved, then the OEF starts to increase. Such increases in the OEF are known as "misery perfusion" and can be observed during the acute stage of cerebral infarction (Fig. 19.3). In the chronic stage of cerebral infarction, misery perfusion in patients with unilateral carotid artery occlusion suggests a high probability of stroke recurrence [6-8]. Powers et al. classified the severity of cerebral ischemia from Stage 0 to Stage II according to CBF, CBV, and OEF [9]. Stage II is equal to the state of misery perfusion. The 5-year stroke recurrence rate for Stage II patients with unilateral steno-occlusive internal carotid artery (ICA) was $70 \%$, whereas it was $20 \%$ for Stage 0 and I patients [8].

\subsection{Infarct Growth in Acute Cerebral Infarction}

The ischemic threshold of CBF has been thoroughly evaluated in both experimental studies and clinical studies. Symon and colleagues revealed a relationship between $\mathrm{CBF}$, neurological deficits, and tissue damage in baboon models of cerebral ischemia [10]. They showed that the electric activity of somatosensory evoked potentials in cerebral tissue was preserved at a CBF above $20 \mathrm{~mL} / 100 \mathrm{~g} / \mathrm{min}(40 \%$ of normal level), whereas it was impaired when the CBF decreased to $10-20 \mathrm{~mL} / 100 \mathrm{~g} / \mathrm{min}$. 
Although this impaired electric activity was reversible by recirculation, irreversible damage resulting from an elevated extracellular potassium concentration and subsequent cell death occurred when the CBF was reduced to less than 6-10 mL/100 g/ min. Astrup, Siesjo, and Symon defined the ischemic penumbra as brain tissue with CBF thresholds between electric $(20 \mathrm{~mL} / 100 \mathrm{~g} / \mathrm{min})$ and membrane failure (6-10 $\mathrm{mL} / 100 \mathrm{~g} / \mathrm{min})$ [11]. In a baboon model, Jones et al. found that a longer period of ischemia was associated with a higher threshold for membrane failure [12]. Their studies indicated that the ischemic penumbra should be restored as early as possible to reduce the volume of cerebral infarction. Clinical SPECT studies have demonstrated the validity of evaluating the ischemic threshold during the acute stage of infarction. Shimosegawa et al. evaluated SPECT images within $6 \mathrm{~h}$ of onset in ischemic stroke patients and revealed that a CBF of less than 30-50\% of that in unaffected brain regions was capable of inducing cerebral infarction [13] (Fig. 19.4). When the CBF was less than $20 \%$ of that in the unaffected hemisphere, the probability of hemorrhagic infarction after recanalization therapy increased [14].

Although the CBF threshold has been established in both experimental and clinical studies, the metabolic threshold and its relation to the development of infarction has not yet been clarified. In a ${ }^{15} \mathrm{O}$ PET study of patients with cerebral infarction where imaging was performed within $6 \mathrm{~h}$ of onset, Shimosegawa et al. demonstrated that infarct growth occurred in brain lesions with a depressed $\mathrm{CMRO}_{2}$ but normal water diffusion on diffusion-weighted imaging (DWI) [15] (Fig. 19.5). Peri-infarct areas with a $\mathrm{CMRO}_{2}$ of less than $45-62 \%$ of that in unaffected brain regions on the initial ${ }^{15} \mathrm{O}$ PET showed volume expansion of the brain infarction at 3 days after onset, and they named this phenomenon "metabolic penumbra." The normal diffusion in these areas indicated that adenosine triphosphate (ATP) synthesis was still preserved to a degree sufficient to maintain an

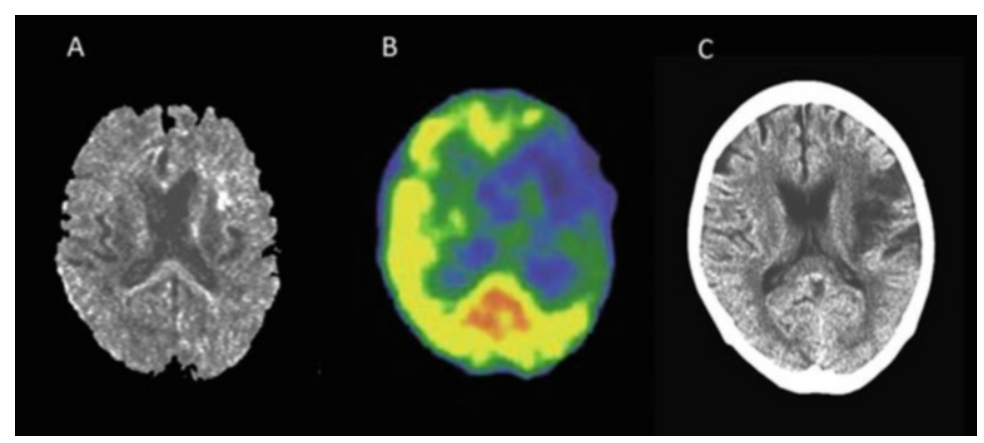

Fig. 19.4 Prediction of cerebral infarction by acute CBF-SPECT. A diffusion-weighted MR image obtained at $1.3 \mathrm{~h}$ after onset (a) demonstrated only a small lesion in the frontal lobe. A ${ }^{99 \mathrm{~m}}$ HMPAO-SPECT image obtained at $2.3 \mathrm{~h}$ after onset (b) showed a broad reduction in CBF in the left cerebral hemisphere. A CBF reduction of more than $50 \%$, compared with the contralateral region, was observed in the left frontal lobe, and this area progressed into a complete infarction visible on a CT image obtained 4 days after onset (c) 


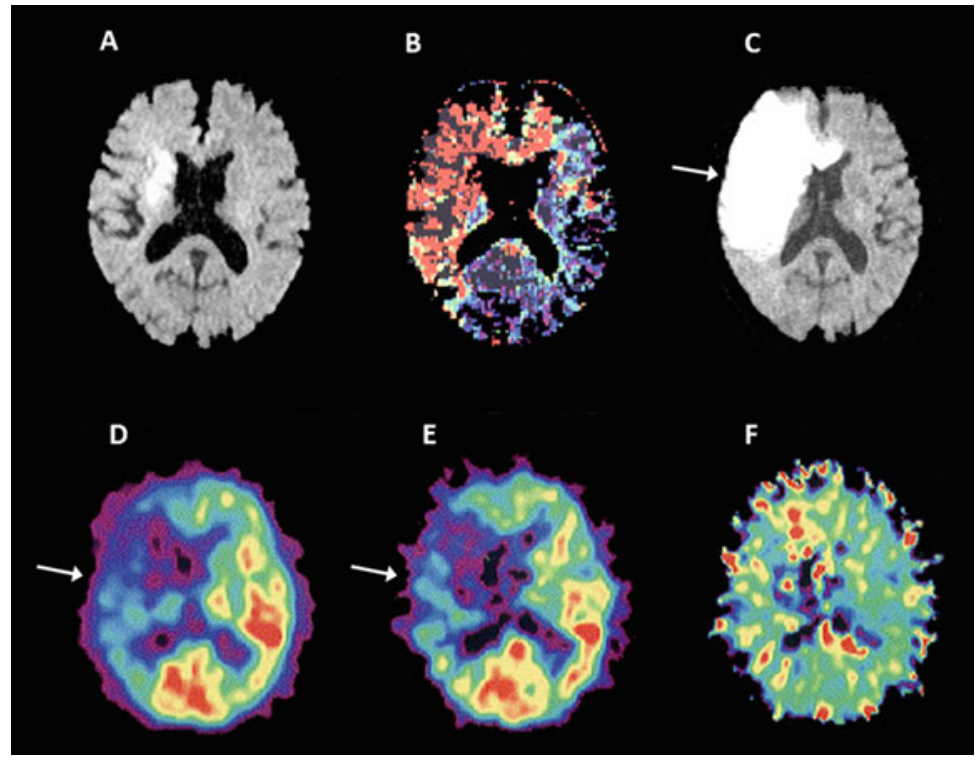

Fig. 19.5 Metabolic penumbra in acute brain infarction. (a) DWI of MRI obtained $4 \mathrm{~h}$ after onset, (b) perfusion-weighted image (PWI) obtained $4 \mathrm{~h}$ after onset, (c) DWI obtained 3 days after onset, (d) $\mathrm{CBF}$ obtained $3 \mathrm{~h}$ after onset, (e) $\mathrm{CMRO}_{2}$ obtained $3 \mathrm{~h}$ after onset, and (f) OEF obtained $3 \mathrm{~h}$ of onset in a patient with right ICA embolic occlusion. An MRI examination indicated PWI-DWI mismatch in the territory of the right ICA. DWI on day 3 indicated an evolution of the infarction within the mismatch. The initial PET examination indicated that the PWI-DWI mismatch lesion exhibited reductions in $\mathrm{CBF}$ and $\mathrm{CMRO}_{2}$ associated with misery perfusion (increased $\mathrm{OEF}$, white arrow). The PWI-DWI mismatch corresponded to suppressed energy metabolism that was still higher than the threshold for ion pump failure (Reprinted from Brain Mapping: An Encyclopedic Reference, Vol. 3/1st edition, Arthur W. Toga (Editor in Chief), Hemodynamic and Metabolic Disturbances in Acute Cerebral Infarction (title)/Clinical Brain Mapping (chapter), written by E. Shimosegawa, p. 829-838, 2015, with permission from Elsevier)

ATP-dependent neuronal membrane ion pump in the area of the evolving infarct as early as $6 \mathrm{~h}$ after onset. Therefore, a metabolic penumbra with a moderate decrease in $\mathrm{CMRO}_{2}$ would be a critical treatment target, using early reperfusion and pharmacological neuroprotection to reduce the volume expansion of the brain infarction.

\subsection{Role of Astrocytic Function in Brain Ischemia}

Recently, some researchers have shed light on the role of glial cells in energy metabolism in the brain. Glutamate is a major excitatory neurotransmitter of the brain, and glutamate in the synaptic cleft is removed by astrocytes surrounding glutaminergic synapses. The removed glutamate is converted into glutamine in astrocytes by glutamine synthetase. Glutamine is released by astrocytes and taken 
up by neuronal terminals, where it is enzymatically reconverted to glutamate and stored in the neurotransmitter pool for the next transmission. This process is called "glutamate-glutamine cycle" and requires ATP [16]. Furthermore, astrocytes play an important role in glycolysis in the brain. Activation by the glutamate transporter on the astrocytic membrane stimulates glucose uptake into astrocytes. This glucose is processed glycolytically, resulting in the release of lactate as an energy substrate for neurons. Lactate produced by this process is transferred to neurons for oxidation (the astrocyte-neuron lactate shuttle: ANLS) [17]. This lactate produces two ATP molecules, which contribute to the Na-K ion pump function and the synthesis of glutamine from glutamate. In ischemic brain where ATP synthesis is restricted, the conversion of glutamate in the synaptic cleft is disturbed. Continuous stimulation by glutamate induces an influx of $\mathrm{Ca}^{2+}$ ion, resulting in anoxic depolarization, and leads to inflammation and apoptosis. Therefore, the glutamate-glutamine cycle and ANLS are deeply related to astrocytic function and plays a critical role in the evolution from penumbra to infarction.

For the specific imaging of astrocyte, acetate is expected to be useful as a selective marker of astrocytic energy metabolism [18, 19]. ${ }^{14} \mathrm{C}$-acetate is rapidly incorporated into glutamine via glutamate by glutamine synthetase localized in astrocytic cells [20]. Hosoi et al. demonstrated that ${ }^{14} \mathrm{C}$-acetate uptake is dramatically decreased in a 3-min ischemia and reperfusion model, indicating that the metabolic and functional impairment of astrocytes continues after the restoration of $\mathrm{CBF}[21] .{ }^{11} \mathrm{C}$-labeled acetate could be a promising PET tracer for the evaluation of astrocytic metabolism in human studies (Fig. 19.6).

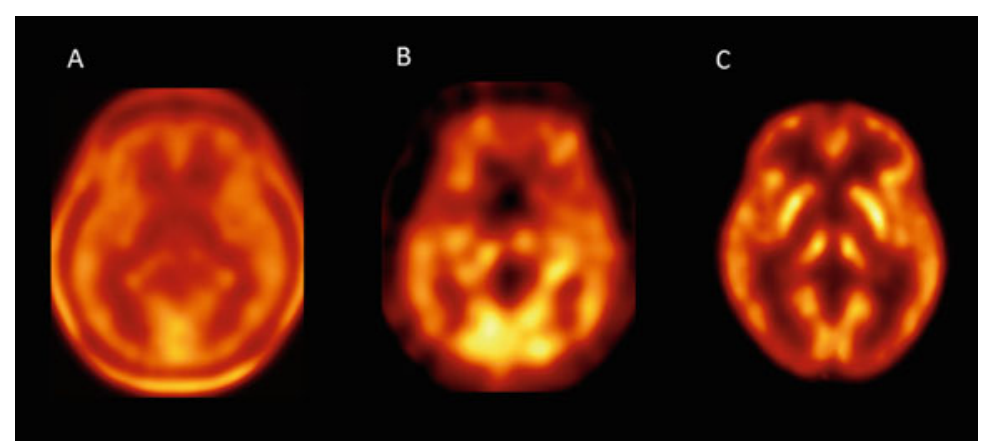

Fig. 19.6 Qualitative and quantitative ${ }^{11} \mathrm{C}$-acetate PET imaging for astrocytic energy metabolism. (a) An averaged ${ }^{11} \mathrm{C}$-acetate PET image (from 0 to $40 \mathrm{~min}$ ) and (b) an averaged Kmono image in a healthy volunteer. The energy metabolism evaluated using the Kmono image was different from the normal oxygen metabolism evaluated using the $\mathrm{CMRO}_{2}$ image (c) 


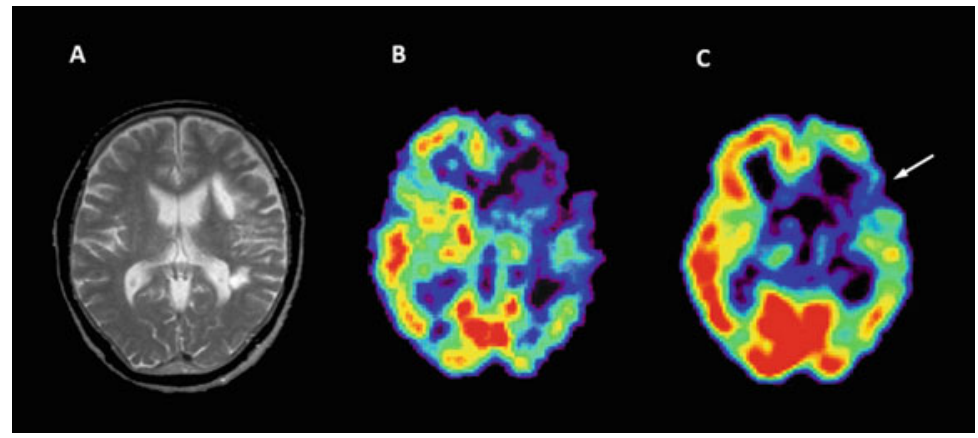

Fig. 19.7 Selective neuronal loss: (a) $T_{2}$-weighted image $\left(T_{2} W I\right)$ in a patient with subcortical infarction of the left putamen 1.5 months after onset, (b) CBF image of the corresponding slice obtained by ${ }^{123}$ I-IMP SPECT, and (c) ${ }^{123}$ I-iomazenil SPECT image of the corresponding slice. The MR image showed no obvious lesion in the left cortical area, whereas ${ }^{123}$ I-iomazenil SPECT demonstrated a decrease in accumulation (white arrow), indicating selective neuronal loss. The $\mathrm{CBF}$ reduction extended beyond the cortical areas of ${ }^{123} \mathrm{I}$-iomazenil reduction (Reprinted from Brain Mapping: An Encyclopedic Reference, Vol. 3/1st edition, Arthur W. Toga (Editor in Chief), Hemodynamic and Metabolic Disturbances in Acute Cerebral Infarction (title)/Clinical Brain Mapping (chapter), written by E. Shimosegawa, p. 829-838, 2015, with permission from Elsevier)

\subsection{Selective Neuronal Loss in Ischemic Brain Injury}

Tissue vulnerability differs among neurons, glial cells, and blood vessels. Selective neuronal necrosis is known to occur in neuron-specific ischemic injury, where other cell components are preserved, and is associated with the expression of apoptosisrelated DNA damages and repair genes [22]. In PET and SPECT imaging, ${ }^{11} \mathrm{C}$ flumazenil and ${ }^{123}$ I-iomazenil are considered to be neuron-specific tracers that bind central benzodiazepine receptors that are specifically localized on the membranes of cortical neurons. Preserved ${ }^{11} \mathrm{C}$-flumazenil accumulation in acute ischemic brain can predict the probability of surviving an infarct [23, 24]. Hatazawa et al. examined ${ }^{123}$ I-iomazenil SPECT in patients with cortical and subcortical infarction. They reported a patient with global aphasia who had a purely subcortical infarction and significantly diminished ${ }^{123}$ I-iomazenil uptake in CT-negative Broca and Wernicke areas [25]. This result indicated that ${ }^{123}$ I-iomazenil SPECT could sensitively detect lesions responsible for clinical symptoms, compared with morphological examinations (Fig. 19.7).

\subsection{Detection of Tissue Hypoxia}

Tissue hypoxia can be visualized using ${ }^{18} \mathrm{~F}$-labeled nitroimidazole derivatives or ${ }^{62 / 64} \mathrm{Cu}$-labeled lipophilic chelate compounds. ${ }^{18} \mathrm{~F}$-fluoromisonidazole $\left({ }^{18} \mathrm{~F}\right.$-FMISO $)$ PET is a representative hypoxic marker. Under hypoxic conditions, ${ }^{18} \mathrm{~F}-\mathrm{FMISO}$ 
passively diffuses into cells and is reduced by nitroreductase enzymes and trapped by intracellular molecules. The retention of ${ }^{18} \mathrm{~F}$-FMISO is inversely proportional to the tissue partial pressure of $\mathrm{O}_{2}$. Takasawa et al. revealed that the selective accumulation of ${ }^{18} \mathrm{~F}$-FMISO was found in permanent and temporal ischemic areas surrounding the ischemic core [26]. They demonstrated that ${ }^{18}$ F-FMISO uptake in the ischemic brain was only elevated during the early phase of middle cerebral artery (MCA) occlusion. After early reperfusion, no demonstrable tracer retention was observed. In patients with an acute MCA territory stroke, Markus et al. reported that ${ }^{18}$ F-FMISO PET showed the temporal evolution of tissue hypoxia [27]. A higher hypoxic volume was observed in the core of the infarct within $6 \mathrm{~h}$ of onset, and the location moved to the periphery or external to the infarct at later time points. They also showed that tissue without ${ }^{18}$ F-FMISO uptake within the final infarct was presumed to have infarcted by the time of the acute ${ }^{18}$ F-FMISO PET. These experimental and clinical results are very interesting because they suggested that ${ }^{18} \mathrm{~F}$ FMISO uptake changes continuously during the course of brain infarction. Since ${ }^{18}$ F-FMISO PET is unable to discriminate between complete infarcted area and non-hypoxic viable tissue during the acute stage of infarction, the timing of the PET examination is likely to be critical for diagnosing whether the tissue is salvageable.

\subsection{Imaging of Neuroinflammation}

In focal brain ischemia, inflammatory reactions mainly occur in the peri-infarct area and lead to an overexpression of peripheral benzodiazepine receptors (PBR)/18$\mathrm{kDa}$ TSPO on the membrane of activated microglia, macrophages, and activated astrocytes. Several PET tracers that specifically bind to TSPO have been developed as biomarkers of neuroinflammation. Imaizumi et al. demonstrated that ${ }^{11} \mathrm{C}-\mathrm{PBR} 28$ accumulated in the peri-infarct lesions of a rat ischemia model, indicating that neuroinflammation does not occur in the ischemic core but in penumbral lesions [28]. In our preclinical study using a temporary MCA occlusion model, ${ }^{11} \mathrm{C}$-DPA713 uptake increased in the area surrounding the infarct core after 4 days of ischemia, where the expression of microglia/macrophages was positive using CD11b immunostaining (Fig. 19.8). In an impressive study, Martín et al. reported that ${ }^{18}$ F-DPA-714 uptake decreased at 7 days after cerebral ischemia in rats treated with minocycline, compared with saline-treated animals [29]. Whether the increased regional microglia/macrophage activation visualized by TSPO PET is a good biomarker remains controversial. TSPO molecular imaging, however, might have diagnostic potential for assessing therapeutic strategies, such as the use of neuroprotective or anti-inflammatory drugs during the acute or subacute stage of cerebral infarction. 


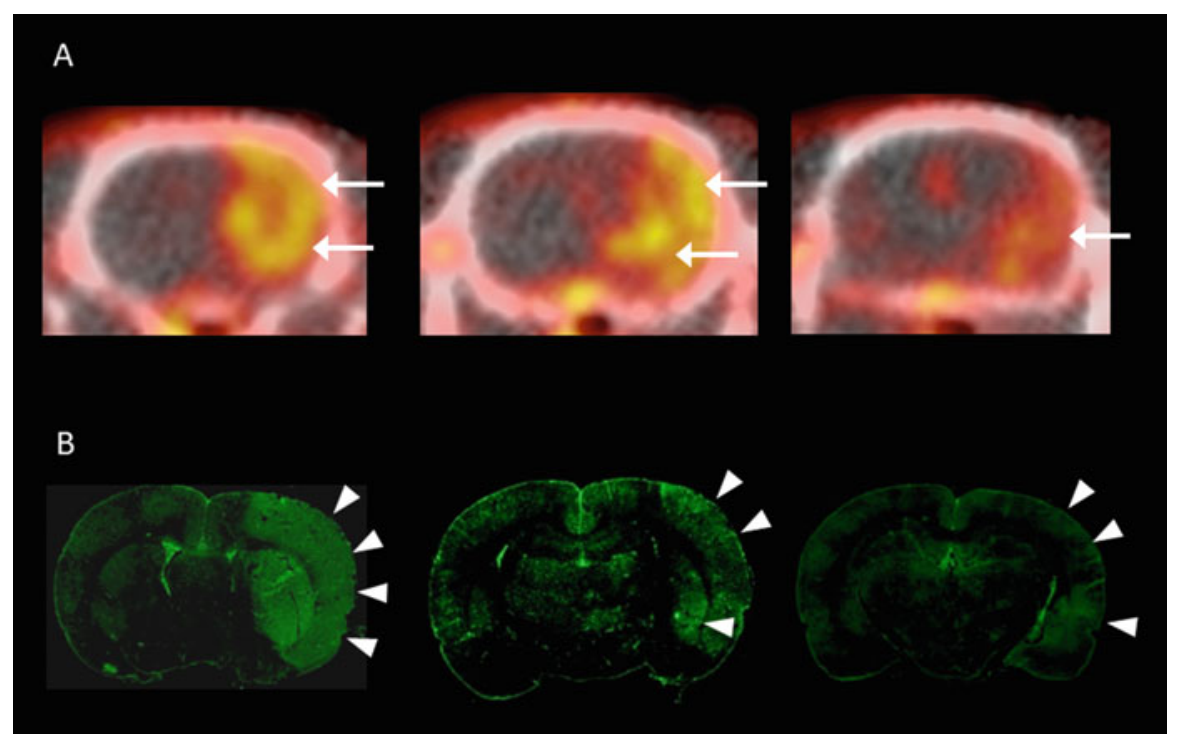

Fig. 19.8 TSPO PET image of rat ischemic model. (a) ${ }^{11} \mathrm{C}$-DPA713 PET and (b) the corresponding CD11b immunostaining image. ${ }^{11} \mathrm{C}$-DPA713 accumulated in the peripheral region of the ischemic core at 4 days after $60 \mathrm{~min}$ of MCA occlusion and reperfusion (white arrows). The CD11b-positive findings agreed with the uptake of ${ }^{11} \mathrm{C}$-DPA713 (white arrow heads), indicating that macrophages/microglia were activated by neuroinflammation after brain ischemia

\subsection{Summary}

Measurements of hemodynamic and metabolic disturbances using PET and SPECT have been utilized to study the acute and chronic stages of cerebral infarction. CBF, $\mathrm{CMRO}_{2}, \mathrm{CBV}, \mathrm{OEF}$, and CVR are basic parameters for estimating CPP reduction. An acute metabolic penumbra (decreased $\mathrm{CMRO}_{2}$ in peri-infarct area on initial PET) and misery perfusion (areas with decreased $\mathrm{CBF}$ with maintained $\mathrm{CMRO}_{2}$ in ischemic brain) during the acute and chronic stages are indicators of evolving infarction. Astrocytes have a protective role against cerebral infarction by reducing the glutamate concentration during ischemia, and ${ }^{11} \mathrm{C}$-acetate PET may provide information regarding glial cell function. Neuron-specific imaging can only be performed using PET and SPECT, and it would be useful to collate the clinical symptoms with neuronal damage. PET tracers for tissue hypoxia and neuroinflammation have been developed and are promising biomarkers for detecting infarct growth and salvageable tissue and are expected to become useful as probes in future therapeutic interventions. 
Open Access This chapter is distributed under the terms of the Creative Commons AttributionNoncommercial 2.5 License (http://creativecommons.org/licenses/by-nc/2.5/) which permits any noncommercial use, distribution, and reproduction in any medium, provided the original author(s) and source are credited.

The images or other third party material in this chapter are included in the work's Creative Commons license, unless indicated otherwise in the credit line; if such material is not included in the work's Creative Commons license and the respective action is not permitted by statutory regulation, users will need to obtain permission from the license holder to duplicate, adapt or reproduce the material.

\section{References}

1. Paulson OB, Strandgaard S, Edvinsson L. Cerebral autoregulation. Cerebrovasc Brain Metab Rev. 1990;2:161-92.

2. Peppiatt CM, Howarth C, Mobbs P, Attwell D. Bidirectional control of CNS capillary diameter by pericytes. Nature. 2006;443:700-4.

3. Lassen NA. The luxury perfusion syndrome and its possible relation to acute metabolic acidosis localized within the brain. Lancet. 1966;2:1113-5.

4. Kuroda S, Houkin K, Kamiyama H, Mitsumori K, Iwasaki Y, Abe H. Long-term prognosis of medically treated patients with internal carotid or middle cerebral artery occlusion: can acetazolamide test predict it? Stroke. 2001;32:2110-6.

5. Ogasawara K, Ogawa A, Yoshimoto T. Cerebrovascular reactivity to acetazolamide and outcome in patients with symptomatic internal carotid or middle cerebral artery occlusion: a xenon-133 single-photon emission computed tomography study. Stroke. 2002;33:1857-62.

6. Yamauchi H, Fukuyama H, Nagahama Y, Nabatame H, Nakamura K, Yamamoto Y, et al. Evidence of misery perfusion and risk for recurrent stroke in major cerebral arterial occlusive diseases from PET. J Neurol Neurosurg Psychiatry. 1996;61:18-25.

7. Grubb Jr RL, Derdeyn CP, Fritsch SM, Carpenter DA, Yundt KD, Videen TO, et al. Importance of hemodynamic factors in the prognosis of symptomatic carotid occlusion. JAMA. 1998;280:1055-60.

8. Yamauchi H, Fukuyama H, Nagahama $Y$, Nabatame H, Ueno M, Nishizawa S, et al. Significance of increased oxygen extraction fraction in five-year prognosis of major cerebral arterial occlusive diseases. J Nucl Med. 1999;40:1992-8.

9. Powers WJ, Grubb Jr RL, Raichle ME. Physiological responses to focal cerebral ischemia in humans. Ann Neurol. 1984;16:546-52.

10. Symon L, Pasztor E, Branston NM. The distribution and density of reduced cerebral blood flow following acute middle cerebral artery occlusion: an experimental study by the technique of hydrogen clearance in baboons. Stroke. 1975;6:476-81.

11. Astrup J, Siesjo BK, Symon L. Thresholds in cerebral ischemia- the ischemic penumbra. Stroke. 1981;12:723-5.

12. Jones TH, Morawetz RB, Crowell RM, Marcoux FW, FitzGibbon SJ, DeGirolami U, et al. Thresholds of focal cerebral ischemia in awake monkeys. J Neurosurg. 1981;54:583-5.

13. Shimosegawa E, Hatazawa J, Inugami A, Fujita H, Ogawa T, Aizawa Y, et al. Cerebral infarction within six hours of onset: prediction of complete infarction with technetium-99mHMPAO SPECT. J Nucl Med. 1994;35:1097-103.

14. Ueda T, Hatakeyama T, Kumon Y, Sasaki S, Uraoka T. Evaluation of risk of hemorrhagic transformation in local intra-arterial thrombolysis in acute ischemic stroke by initial SPECT. Stroke. 1994;25:298-303.

15. Shimosegawa E, Hatazawa J, Ibaraki M, Toyoshima H, Suzuki A. Metabolic penumbra in acute brain infarction: a correlation with infarct growth. Ann Neurol. 2005;57:495-504. 
16. Dienel GA, Cruz NF. Astrocyte activation in working brain: energy supplied by minor substrates. Neurochem Int. 2006;48:568-95.

17. Pellerin L, Magistretti P. Sweet sixteen for ANLS. J Cereb Blood Flow Metab. 2012;32: 1152-66.

18. Muir D, Berl S, Clarke DD. Acetate and fluoroacetate as possible markers for glial metabolism in vivo. Brain Res. 1986;380:336-40.

19. Cerdan S, Kunnecke B, Seelig J. Cerebral metabolism of $\left[1,2-{ }^{13} \mathrm{C} 2\right]$ acetate as detected by in vivo and in vitro ${ }^{13} \mathrm{C}$ NMR. J Biol Chem. 1990;265:12916-26.

20. Martinez Hernandez A, Bell KP, Norenberg MD. Glutamine synthetase: glial localization in brain. Science. 1977;195:1356-8.

21. Hosoi R, Kashiwagi Y, Tokumura M, Abe K, Hatazawa J, Inoue O. Sensitive reduction in $14 \mathrm{C}$-acetate uptake in a short-term ischemic rat brain. J Stroke Cerebrovasc Dis. 2007;16: $77-81$.

22. Nedergaard M. Neuronal injury in the infarct border: a neuropathological study in the rat. Acta Neuropath (Berl). 1987;73:267-74.

23. Heiss WD, Kracht LW, Thiel A, Grond M, Pawlik G. Penumbral probability thresholds of cortical flumazenil binding and blood flow predicting tissue outcome in patients with cerebral ischaemia. Brain. 2001;124:20-9.

24. Guadagno JV, Jones PS, Aigbirhio FI, Wang D, Fryer TD, Day DJ, et al. Selective neuronal loss in rescued penumbra relates to initial hypoperfusion. Brain. 2008;131:2666-78.

25. Hatazawa J, Satoh T, Shimosegawa E, Okudera T, Inugami A, Ogawa T, et al. Evaluation of cerebral infarction with iodine 123-iomazenil SPECT. J Nucl Med. 1995;36:2154-61.

26. Takasawa M, Beech JS, Fryer TD, Hong YT, Hughes JL, Igase K, et al. Imaging of brain hypoxia in permanent and temporary middle cerebral artery occlusion in the rat using ${ }^{18} \mathrm{~F}$-fluoromisonidazole and positron emission tomography: a pilot study. J Cereb Blood Flow Metab. 2007;27: $679-89$.

27. Markus R, Reutens DC, Kazui S, Read S, Wright P, Chambers BR, et al. Topography and temporal evolution of hypoxic viable tissue identified by ${ }^{18} \mathrm{~F}$-fluoromisonidazole positron emission tomography in humans after ischemic stroke. Stroke. 2003;34:2646-52.

28. Imaizumi M, Kim HJ, Zoghbi SS, Briard E, Hong J, Musachio JL, et al. PET imaging with [11C]PBR28 can localize and quantify upregulated peripheral benzodiazepine receptors associated with cerebral ischemia in rat. Neurosci Lett. 2007;411:200-5.

29. Martín A, Boisgard R, Kassiou M, Dollé F, Tavitian B. Reduced PBR/TSPO expression after minocycline treatment in a rat model of focal cerebral ischemia: a PET study using $\left[{ }^{18} \mathrm{~F}\right] \mathrm{DPA}-$ 714. Mol Imaging Biol. 2010;13:10-5. 